\title{
Vitamin D supplement use and associated demographic, dietary and lifestyle factors in 8024 South Asians aged 40-69 years: analysis of the UK Biobank cohort
}

\author{
Andrea L Darling*, David J Blackbourn, Kourosh R Ahmadi and Susan A Lanham-New \\ Department of Nutritional Sciences, School of Biosciences and Medicine, Faculty of Health and Medical Sciences, \\ University of Surrey, Guildford, Surrey, GU2 7XH, UK
}

Submitted 9 October 2017: Final revision received 30 March 2018: Accepted 30 April 2018: First published online 25 June 2018

\begin{abstract}
Objective: Vitamin D deficiency (serum 25-hydroxyvitamin $\mathrm{D}<25 \mathrm{nmol} / \mathrm{l}$ ) is extremely common in Western-dwelling South Asians but evidence regarding vitamin D supplement usage in this group is very limited. This work identifies demographic, dietary and lifestyle predictors associated with vitamin D supplement use.

Design: Cross-sectional analysis of baseline vitamin D supplement use data.

Setting: UK Biobank cohort.

Subjects: In total, 8024 South Asians (Bangladeshi, Indian, Pakistani), aged 40-69 years.

Results: Twenty-three per cent of men and 39\% of women $(P<0.001)(22 \%$ of Bangladeshis, $32 \%$ of Indians, $25 \%$ of Pakistanis $(P<0 \cdot 001))$ took a vitamin-Dcontaining supplement. Median vitamin D intakes from diet were low at $1 \cdot 0$ $3.0 \mu \mathrm{g} / \mathrm{d}$, being highest in Bangladeshis and lowest in Indians $(P<0 \cdot 001)$. Logistic regression modelling showed that females had a higher odds of vitamin $D$ supplement use than males (OR $=2 \cdot 02 ; 95 \%$ CI 1.79, 2.28). A lower supplement usage was seen in younger persons ( $40-60$ years $v$. $>60$ years: $\mathrm{OR}=0.75 ; 95 \% \mathrm{CI}$ $0.65,0.86)$ and in those living outside Greater London (OR $=0.53$ to 0.77), with borderline trends for a lower BMI, higher oily fish intake and higher household income associated with increased odds of vitamin D supplement use.

Conclusions: Vitamin D supplements were not used by most South Asians and intakes from diet alone are likely to be insufficient to maintain adequate vitamin D status. Public health strategies are now urgently required to promote the use of vitamin D supplements in these specific UK South Asian subgroups.
\end{abstract}

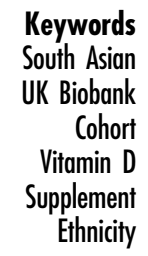

Vitamin D insufficiency $(<50 \mathrm{nmol} / \mathrm{l})$ is highly prevalent worldwide $^{(1)}$ and has been associated in observational studies with an increased risk of a wide range of chronic diseases, including osteoporosis, cancer, CVD, diabetes, multiple sclerosis and infectious diseases ${ }^{(2)}$, albeit evidence from randomised controlled trials is required to confirm direction of causality.

The economic burden of vitamin D deficiency is potentially phenomenal. In 2009 Grant et al. calculated a projected saving of $€ 187$ billion per year if all Western Europeans had a serum 25-hydroxyvitamin D (25(OH)D) concentration of $40 \mathrm{ng} / \mathrm{ml}(100 \mathrm{nmol} / \mathrm{l})^{(3)}$, making reduction of vitamin D deficiency a high public health priority. Note that this is high target for vitamin D status (most guidelines $^{(4,5)}$ recommend 25 or $50 \mathrm{nmol} / 1$ as a definition of vitamin D sufficiency), but the Grant et al. paper illustrates the point that vitamin D deficiency is costly to society.

Recent studies have highlighted high rates of vitamin D deficiency $(<50 \mathrm{nmol} / \mathrm{l})$ in Western-dwelling South Asians in North America ${ }^{(6-8)}$, Europe $^{(9-18)}$ and Australasia ${ }^{(19)}$. This is likely to be underpinned in large part by darker skin pigmentation $^{(20)}$, low sun exposure of the skin due to dress coverage and sun avoidance behaviour ${ }^{(21,22)}$, low dietary exposure to foods containing vitamin $\mathrm{D}^{(9,23)}$ and high prevalence of overweight/obesity $\left(\mathrm{BMI} \geq 25 \mathrm{~kg} / \mathrm{m}^{2}\right)^{(24)}$. Improvement in vitamin D status is likely to help reduce the incidence of a variety of chronic diseases common in Western-dwelling South Asians, such as type 2 diabetes and $\mathrm{CVD}^{(25)}$.

To tackle the problem of vitamin $\mathrm{D}$ deficiency $(<50 \mathrm{nmol} / \mathrm{l})$ in Europe, the European Food Safety 
Authority recommended an intake of $15 \mu \mathrm{g} / \mathrm{d}$ (600 IU/d) for all adults ${ }^{(5)}$. In the UK, the Scientific Advisory Committee on Nutrition (SACN) recently advised a Recommended Nutrient Intake for vitamin D of $10 \mu \mathrm{g} / \mathrm{d}$ for the whole UK population aged 4 years or over ${ }^{(4)}$. However, the UK diet is low in vitamin $\mathrm{D}$, with the National Diet and Nutrition Survey (NDNS) reporting intakes of $1 \cdot 8-3 \cdot 2 \mu \mathrm{g} / \mathrm{d}$ in males and $1.8-2.3 \mu \mathrm{g} / \mathrm{d}$ in females, depending on survey year and age group ${ }^{(26)}$. Therefore, in practice the European Food Safety Authority and SACN advice translates into using a vitamin D supplement of cholecalciferol or ergocalciferol of up to $10-15 \mu \mathrm{g} / \mathrm{d}$ for most people who do not have a daily intake of at least one 100-150 g portion oily fish (e.g. $100 \mathrm{~g}$ of farm-raised salmon $=10 \mu \mathrm{g}$ of vitamin $\mathrm{D}^{(27)}$ ) or substantial summer sun exposure. Other dietary sources of vitamin D (e.g. eggs, fortified breakfast cereal, cereals, fortified spreads) can also contribute to getting an intake of $10 \mu \mathrm{g} / \mathrm{d}$ but are available only in smaller amounts in the diet (e.g. 1 egg contains $1 \mu \mathrm{g}$ of vitamin D).

In the SACN deliberations, there was a considerable lack of evidence regarding vitamin D status in South Asians to justify a separate recommendation for South Asians in the $\mathrm{UK}^{(4)}$. However, it is certainly plausible that such a recommendation be necessary considering South Asians' higher vitamin D risk factors than other UK ethnic groups. The SACN report ${ }^{(4)}$ called for more information regarding the vitamin D requirements in South Asians and there is a clear need for specific insights into the demographic, dietary and lifestyle factors associated with supplement usage in UK South Asians.

To our knowledge, there are no studies that have reported on the use of vitamin D supplementation and its predictors among UK or other Western-dwelling South Asian adults specifically. Moreover, data on vitamin D intakes in different UK-based South Asian groups are extremely limited. One study found a vitamin D intake of $1.4 \mu \mathrm{g} / \mathrm{d}$ in South Asian boys, with no difference between those of Bangladeshi, Indian or Pakistani ethnicity ${ }^{(23)}$. Intakes of vitamin D in South Asian women have been estimated to be $1 \cdot 2-2 \cdot 2 \mu \mathrm{g} / \mathrm{d}^{(9,21)}$ depending on study and season.

In the present study our objective was twofold: first, using data from the UK Biobank cohort (8024 South Asians) to quantify dietary intakes of vitamin $\mathrm{D}$ and assess the occurrence of vitamin-D-containing supplement use among three different South Asian population groups (Bangladeshi, Indian and Pakistani); and second, to assess how demographic, dietary and lifestyle factors are associated with vitamin-D-containing supplement use among these populations. We hypothesised that vitamin D intakes would be lower in the Indian group than in the Bangladeshi and Pakistani groups due to the common consumption of vegetarian and vegan diets in Indian populations. Based upon known predictors of vitamin D supplement users in other ethnic groups ${ }^{(28,29)}$, we hypothesised that women, and those of higher socio-economic status, would be more likely to use a vitamin D supplement than men, and those of a lower socio-economic status.

\section{Methods}

\section{UK Biobank cobort}

Briefly, the UK Biobank (www.ukbiobank.ac.uk/) is a large ongoing UK-wide cohort of over 500000 individuals aiming to investigate exposures which impact on health outcomes in middle and older life ${ }^{(30)}$. The data collection has included a wide range of exposures and outcomes including demographic, dietary and lifestyle factors as well as genetic and biochemical markers. The participants were aged 40-69 years at the baseline visit and were recruited during the period 2006-2010 via central National Health Service (NHS) registers ${ }^{(30)}$. In the current cross-sectional analysis, all UK Biobank participants were eligible for

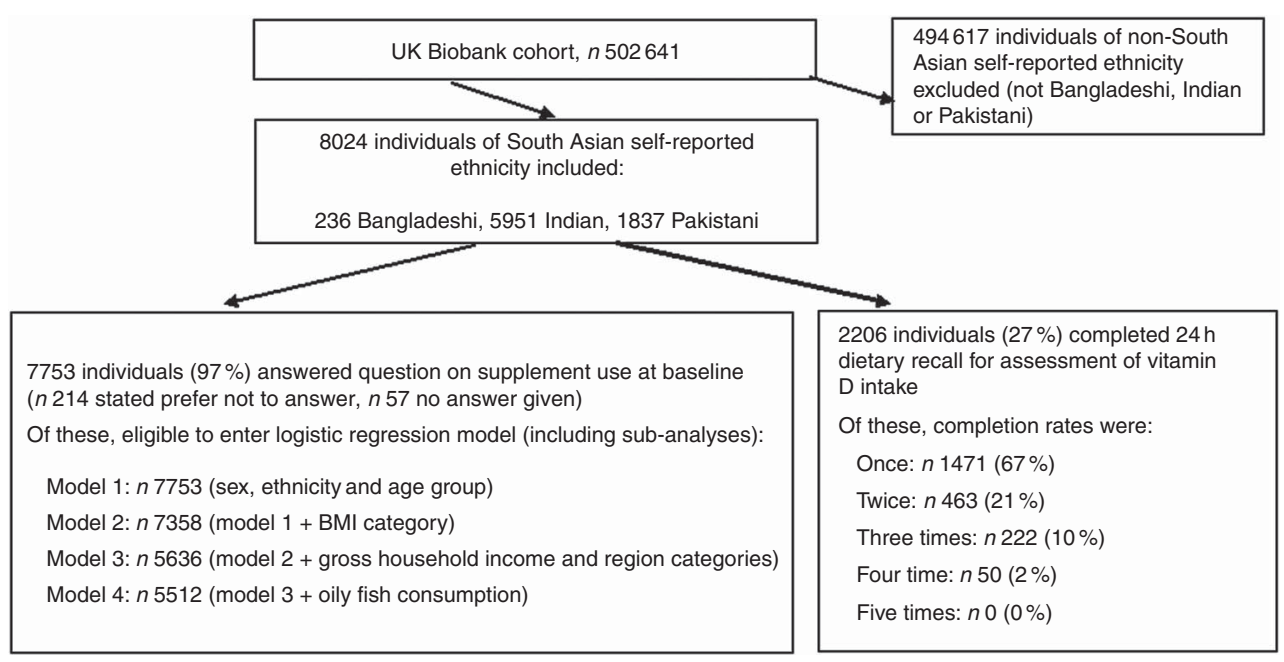

Fig. 1 Flowchart of UK Biobank participants: numbers of participants in the analyses as compared with the whole cohort $(n$ 8024) 
inclusion if they self-reported as of 'Bangladeshi', 'Indian' or 'Pakistani' ethnicity, giving 8024 South Asians (3730 women, 4294 men) of whom 236 were Bangladeshi, 5951 were Indian and 1837 were Pakistani. No other inclusion or exclusion criteria were used. See Fig. 1 for illustration of the numbers of participants entering the current analysis from the whole UK Biobank cohort.

\section{Dietary questionnaires}

\section{$24 \mathrm{~b}$ dietary recall questionnaire}

Baseline vitamin D intake in the UK Biobank was estimated from a participant-completed $24 \mathrm{~h}$ recall questionnaire which measured the frequency of foods consumed the previous day. The questionnaire covered the following food groups: Hot and cold beverages; Alcoholic beverages; Cereal; Milk, eggs and cheese; Bread, pasta and rice; Soups, snacks and pastries; Meat and fish; Vegetarian alternatives; Spreads, sauces and cooking oils; and Fruit and vegetables ${ }^{(31)}$. Therefore, the main food groups that contain vitamin D were included. The nutrient intake was calculated by multiplying the weight of food consumed (grams) by the vitamin D content per gram as defined by the 5th edition of McCance and Widdowson's The Composition of Foods ${ }^{(32,33)}$. This questionnaire has previously been validated against other $24 \mathrm{~h}$ recall methods and compares well for the estimation of most nutrients (10\% difference or less between the methods) ${ }^{(32)}$. As vitamin $\mathrm{D}$ is likely to be poorly estimated based on one $24 \mathrm{~h}$ dietary recall, we decided to use the median vitamin D intake calculated for each participant across all dietary recalls completed.

This questionnaire included questions about how frequently the participant had consumed 200 foods and drinks (e.g. 'Did you eat any bread or crackers yesterday?'). The questionnaire also asked about supplement use but these data were not included in the calculation of the nutrient intake. We did not include this in our calculation of how many people were on supplements because only one person who had not originally answered the touchscreen question (with a valid response) on supplement use answered this question (so it did not add anything to the analysis). The last 70000 participants completed this questionnaire at the baseline visit using the touchscreen computer, and all participants who had provided the investigators with email addresses were invited to complete the same questionnaire from their home computer on four subsequent occasions from February 2011 to April 2012 ${ }^{(31)}$, meaning that the maximum number of completions was five times. Invites were timed to ensure different days of the week were targeted on each occasion.

\section{Food frequency (touchscreen) questionnaire}

Frequency of consumption of different food groups was recorded via the Oxford WebQ $\mathrm{FFQ}^{(34)}$ on the touchscreen computer at the baseline visit. This was used only to code participants as vegetarian or not, and for estimation of oily fish intake for the logistic regression modelling. For the purposes of the current analysis, we defined individuals as vegetarian (no consumption of meat or fish) based on them having answered 'never consumes' to all of the following food categories on the touchscreen questionnaire: oily fish, non-oily fish, processed meat, poultry, pork, beef, lamb and mutton. This was because these questions were completed by 7296 South Asians, whereas only 571 South Asians completed the question on special diets which had been part of the $24 \mathrm{~h}$ recall questionnaire, making use of the food categories from the touchscreen questionnaire a more reliable source for determining meat- and fish-eating status.

\section{Statistical analysis}

Within-cohort supplement use prevalence and vitamin D intake

Figures were created using GraphPad Prism version 7.02. All statistical analyses were conducted using the statistical software package IBM SPSS Statistics version 21, with independent $t$ tests (for sex) or one-way ANOVA (for ethnicity), to assess group differences, unless otherwise stated. The $\chi^{2}$ test was used to test for associations between usage of vitamin-D-containing supplements by sex and ethnicity. For vitamin D intake, we used nonparametric tests instead of log-transformed data due to potential loss of data from participants who had zero values, a valid intake for vitamin $\mathrm{D}$. All other continuous variables were normally distributed and so did not require log transformation prior to parametric statistical analysis.

Previous studies have defined 'vitamin-D-containing supplements' as any supplement containing vitamin D, including combined calcium and vitamin D and multivitamin and mineral $^{(28,35)}$, some also including fish-body oils and fish-liver oils ${ }^{(35)}$. However, due to the nature of the data available in the UK Biobank we did not include fish-body or fish-liver oil, and defined 'vitamin-D-containing supplements' as just multivitamin and mineral supplements and all single vitamin D supplements, assuming all multivitamin and mineral supplements to contain vitamin D. We did not include mineral-only supplements as these rarely contain vitamin D. See the online supplementary material, Supplemental File 1, for further information regarding the rationale for this decision.

\section{Variables associated with supplement use}

Logistic regression analysis was used to examine the association of sex, ethnicity and age with supplement usage (binary coded as vitamin-D-containing supplement user $v$. non-user; model 1). Next, BMI category was added to the model (model 2), followed by socio-economic 
factors (gross annual household income and geographical region) in model 3. Finally, in model 4 , dietary variables were added (oily fish consumption and vegetarianism). As this was an exploratory analysis, model variables were chosen based on a confirmed difference between vitaminD-containing supplement users and non-users, after Bonferroni adjustment for multiple testing ( $\alpha=0.005$; online supplementary material, Supplemental Table 1). See Supplemental File 1 for details of how categorical variables were recoded from those of the original Biobank data and how continuous variables were converted to categorical variables.

Due to the relatively large sample sizes, and the subsequent risk of the analyses being statistically overpowered, confidence intervals rather than $P$ values were used wherever possible to assess statistical significance in the logistic regression models. It was planned that subanalyses would be conducted for single vitamin D supplements and multivitamin and mineral supplements separately to see if the variables associated with usage varied by supplement sub-type.

\section{Results}

\section{Participant characteristics}

Mean age and BMI were similar in males and females (see online supplementary material, Supplemental Table 2), with both sexes on average being classified as overweight. South Asian-specific waist-to-hip ratio cut-off points $(0.8 \mathrm{~cm} \text { for women and } 0.9 \mathrm{~cm} \text { for men })^{(36)}$ classified both sexes as centrally obese. The three ethnic groups were similar in age, BMI and waist-to-hip ratio (Table 1), with all groups being obese on average (South Asian BMI cut-off used for obesity: $\left.\geq 25 \mathrm{~kg} / \mathrm{m}^{2}\right)^{(37)}$ and having a waist-to-hip ratio indicating central obesity. The following percentages of females and males respectively had a BMI of $26-29 \mathrm{~kg} / \mathrm{m}^{2}$ (34\%, $41 \%)$ or of $\geq 30 \mathrm{~kg} / \mathrm{m}^{2}$ (30\%, 24\%). The following percentages of Bangladeshis, Indian and Pakistanis respectively had a BMI of $26-29 \mathrm{~kg} / \mathrm{m}^{2}$ (39\%, 37\%, 39\%) or of $\geq 30 \mathrm{~kg} / \mathrm{m}^{2}$ (19\%, 24\%, 35\%).

See the online supplementary material, Supplemental File 2, for further details of participant characteristics by sex and ethnicity.

\section{Characteristics by sex}

Our analyses showed an association between sex and oily fish intake, with women being 1.5 times more likely to 'never eat oily fish' and half as likely to eat oily fish once or more daily than were men $(P<0 \cdot 001$; online supplementary material, Supplemental Table 3). Women were also nearly twice as likely to be vegetarian $(P<0 \cdot 001)$. See the online supplementary material, Supplemental File 2, for further details of other participant characteristics by sex.

\section{Characteristics by etbnicity}

There was a higher proportion of females in the Indian group (49\%) than in the Bangladeshi (31\%) and Pakistani (39\%) groups (Table 2), which is important to bear in mind when interpreting the results between ethnic groups. Oily fish intake varied among the three ethnic groups $(P<0.001)$, with $10 \%$ of Bangladeshis ( $n$ 23) consuming oily fish daily compared with $<1 \%$ of Indians ( $n$ 17) and $<1 \%$ of Pakistanis ( $n$ 6). A higher proportion of Indians were vegetarians (30\%) compared with Bangladeshis and Pakistanis ( $<1 \%$ vegetarian; $P<0.001$ ).

\section{Vitamin $D$ intake and supplement use}

There was little difference in vitamin D intake by sex, with a median (interquartile range) of $1.0(1.6)$ and $1.2(2 \cdot 0) \mu \mathrm{g} / \mathrm{d}$ in females and males, respectively (Mann-Whitney $U$ test, $P=0.002, n$ 2206). However, vitamin $\mathrm{D}$ intake differed between the three ethnic groups (Kruskal-Wallis test, $P<0 \cdot 001, n 2206)$, with a median (interquartile range) of $3.0(3.7), 1.0(1.6)$ and $1.9(2.0) \mu \mathrm{g} / \mathrm{d}$ in the Bangladeshi, Indian and Pakistani groups, respectively, and Dunn's post boc tests showing differences between all three groups (Table 1).

A $\chi^{2}$ analysis showed that women were more likely to use a vitamin-D-containing supplement than were men (39\% usage in women $v .23 \%$ usage in men; $P<0 \cdot 001, n$ 7553, Fig. 2). Persons of Indian ethnicity were more likely to use a vitamin-D-containing supplement than those of Bangladeshi and Pakistani ethnicity $(P<0 \cdot 001, n 7553$, Fig. 2). Specifically, $22 \%$ of Bangladeshi, $32 \%$ of Indian and $25 \%$ of Pakistani participants used a supplement containing vitamin D.

\section{Demographic, dietary and lifestyle factors associated with vitamin $D$ containing supplement use}

In our first model, which included sex, ethnicity and age variables (Table 3), sex had the strongest association with supplement use, with a $2 \cdot 13$ (95\% CI 1.93, 2.36) times higher odds in women than in men (reference category). Younger persons (40-59 years) had odds of supplement use of only $0.79(95 \%$ CI $0.71,0.88)$ compared with those aged $\geq 60$ years (reference category). Pakistanis $(\mathrm{OR}=$ 0.77; $95 \%$ CI 0.68, 0.87), but not Bangladeshis (OR = 0.73; $95 \%$ CI $0.52,1.01)$, had lower supplement use than did Indians (reference category). When BMI was added to the model (model 2), BMI $\leq 25 \cdot 4 \mathrm{~kg} / \mathrm{m}^{2}$ was associated with an increased odds of supplement use $(1 \cdot 25 ; 95 \%$ CI $1 \cdot 10$, 1.43) compared with BMI $>29.4 \mathrm{~kg} / \mathrm{m}^{2}$ (reference category) and the odds for Pakistani (compared with Indian) was reduced in size $(\mathrm{OR}=0.80 ; 95 \%$ CI 0.70, 0.90).

For model 3, when gross annual household income and region were added to model 2 , sex and age were still associated variables, but the lower limit of the $95 \%$ CI for BMI $<25.4 \mathrm{~kg} / \mathrm{m}^{2}(1.03)$ was now very close to the null (1.00) and Pakistani ethnicity did not now differ from 
Indian ethnicity (OR=0.95; 95\% CI 0.81, 1.11; Table 4). An income of $<£ 18000$ per year was associated with a reduced odds of supplement use ( $\mathrm{OR}=0 \cdot 80 ; 95 \% \mathrm{CI} 0 \cdot 67$, 0.94 ) as compared with $\geq \$ 52000$ (reference category). All geographical regions were associated with supplement use, having a lower odds of supplement use ranging from $\mathrm{OR}=0.52(95 \% \mathrm{CI} 0.30,0.90)$ to $\mathrm{OR}=0.76(95 \% \mathrm{CI} 0.65$, 0.89) compared with Greater London (reference category).

For model 4, vegetarianism and oily fish consumption were trialled, but the data fit was better with just oily fish consumption in the model (see online supplementary material, Supplemental File 2, for full details). Sex, region, household income and age had similar effect sizes to that previously, and oily fish consumption of less than once per week was associated with reduced odds of supplement use (OR $=0.78 ; 95 \% \mathrm{CI} 0.63,0.96)$ as compared with two or more times per week (reference), but the upper limit of the $95 \% \mathrm{CI}(0.96)$ was close to the null. See online supplementary material, Supplemental File 2, for further information on the final model as well as for the results of sub-analyses by vitamin-D-containing supplement type (Supplemental Table 4).

\section{Discussion}

There is currently little, if indeed any data on vitamin-Dcontaining supplement use and associated demographic, dietary and lifestyle factors in Western-dwelling South Asian populations. Our findings from this large research population of UK South Asians suggest that female sex, being over 60 years old and living in Greater London were associated with increased odds of using a supplement containing vitamin D. We also found borderline trends for a lower BMI, higher oily fish intake and higher household income being associated with higher likelihood of vitaminD-containing supplement use.

Our findings support previous research in white Caucasian groups, showing female and older age being associated with supplement use ${ }^{(38,39)}$. These sex and age differences are perhaps not surprising considering vitamin $\mathrm{D}$ and calcium have been historically promoted more intensively to women than men, due to increased osteoporosis risk in women, and older age may intensify personal perception of increased osteoporosis or disease risk per $s e^{(40)}$ relative to middle-aged persons.

Our finding that the majority of South Asians in the UK Biobank cohort do not use vitamin-D-containing supplements also supports previous studies in South Asians in other Western countries which have looked at cod-liver oil supplement use. For example, a study of Norway-dwelling South Asians by Holvik et al. found that $15 \%$ of men and $15 \%$ of women used cod-liver oil daily, with $58 \%$ of men and $60 \%$ of women not using cod-liver oil supplements ${ }^{(18)}$. Similarly, a study of Sri Lankans living in Norway found that $20 \%$ took a cod-liver oil supplement daily ${ }^{(41)}$. A UK study 
Table 2 Characteristics of 8024 South Asian UK Biobank participants by ethnic group: categorical data, split by ethnic subgroup (Bangladeshi, Indian, Pakistani)

\begin{tabular}{|c|c|c|c|c|c|c|c|}
\hline & \multicolumn{2}{|c|}{ Bangladeshi $(n$ 236) } & \multicolumn{2}{|c|}{ Indian ( $n$ 5951) } & \multicolumn{2}{|c|}{ Pakistani ( $n$ 1837) } & \multirow[b]{2}{*}{$P^{*}$} \\
\hline & $\%$ & $n$ & $\%$ & $n$ & $\%$ & $n$ & \\
\hline \multicolumn{8}{|l|}{ Sex } \\
\hline Female & 31 & 74 & 49 & 2939 & 39 & 717 & $<0.001$ \\
\hline Male & 69 & 162 & 51 & 3012 & 61 & 1120 & \\
\hline Current smoker (\% yes; any frequency) & 27 & 234 & 7 & 5933 & 12 & 1832 & $<0.001$ \\
\hline \multicolumn{8}{|l|}{ Oily fish intake } \\
\hline Never & 4.4 & 10 & 38 & 2221 & 22 & 370 & $<0.001$ \\
\hline$<$ Once per week & 17 & 38 & 26 & 1504 & 39 & 667 & \\
\hline Once per week & 28 & 64 & 26 & 1483 & 31 & 539 & \\
\hline $2-4$ times per week & 30 & 67 & 9 & 529 & 8 & 130 & \\
\hline $5-6$ times per week & 11 & 25 & 1 & 40 & 1 & 9 & \\
\hline Once or more daily & 10 & 23 & $<1$ & 17 & $<1$ & 6 & \\
\hline Fair/poor health (\% yes) & 59 & 223 & 39 & 5866 & 52 & 1798 & $<0.001$ \\
\hline Vegetarian (\% yes) & 0.5 & 1 & 30 & 1474 & 0.5 & 9 & $<0.001$ \\
\hline Postmenopausal (\% yes of females) & 57 & 61 & 64 & 2594 & 50 & 606 & $<0.001$ \\
\hline Born outside UK and Republic of Ireland (\% yes) & 95 & 212 & 90 & 5257 & 88 & 1544 & 0.001 \\
\hline \multicolumn{8}{|l|}{ Of which: } \\
\hline \% Immigrated before 1959 & 1 & 2 & 3 & 134 & 1 & 21 & $<0.001$ \\
\hline \% Immigrated 1960-1979 & 46 & 96 & 73 & 3809 & 60 & 899 & \\
\hline \% Immigrated 1980-1999 & 44 & 92 & 17 & 876 & 27 & 404 & \\
\hline$\%$ Immigrated 2000 onwards & 9 & 20 & 7 & 388 & 12 & 184 & \\
\hline \multicolumn{8}{|l|}{ Gross annual household income $(£)$} \\
\hline$<18000$ & 61 & 93 & 26 & 1171 & 50 & 648 & $<0.001$ \\
\hline $18000-30999$ & 13 & 20 & 25 & 1116 & 20 & 267 & \\
\hline $31000-51999$ & 16 & 24 & 22 & 972 & 15 & 193 & \\
\hline $52000-100000$ & 9 & 13 & 20 & 881 & 11 & 147 & \\
\hline$>100000$ & 1 & 2 & 7 & 302 & 4 & 55 & \\
\hline \multicolumn{8}{|l|}{ Townsend Deprivation Index } \\
\hline$\leq$ UK median (less deprived) & 20 & 47 & 41 & 2445 & 28 & 514 & $<0.001$ \\
\hline > UK median (more deprived) & 80 & 189 & 59 & 3499 & 72 & 1321 & \\
\hline \multicolumn{8}{|l|}{ Biobank assessment centre } \\
\hline Leeds & 6 & 14 & 7 & 399 & 14 & 249 & $<0.001$ \\
\hline Hounslow & 12 & 28 & 36 & 2123 & 16 & 292 & \\
\hline Croydon & 11 & 26 & 13 & 790 & 7 & 119 & \\
\hline Birmingham & 15 & 35 & 15 & 898 & 17 & 318 & \\
\hline Other & 56 & 133 & 29 & 1741 & 47 & 859 & \\
\hline \multicolumn{8}{|l|}{ Region } \\
\hline Northern England & 28 & 65 & 18 & 1066 & 41 & 751 & $<0.001$ \\
\hline Southern England & 6 & 13 & 8 & 492 & 7 & 125 & \\
\hline Wales & 3 & 6 & 1 & 71 & 2 & 39 & \\
\hline Scotland & 2 & 4 & 2 & 98 & 5 & 83 & \\
\hline The Midlands & 17 & 40 & 20 & 1202 & 22 & 403 & \\
\hline Greater London & 46 & 108 & 51 & 3022 & 24 & 436 & \\
\hline
\end{tabular}

${ }^{*}$ Based on $x^{2}$ test.

which recorded vitamin D supplement use in South Asians (but did not assess predictors of usage) found that only 2-6\% of South Asian women used a vitamin D supplement at baseline $^{(21)}$. In contrast, one study in Canada ${ }^{(42)}$ found that only $17 \%$ of South Asians did not take vitamin-D-containing supplements. The discrepancy between the latter study's finding and that of our own, the other UK study and the two Norwegian studies is not easy to explain but could be due to the older age in the Canadian study (60-90 years) ${ }^{(42)}$ compared with $30-60$ years $^{(18,41)}$ in the two Norwegian studies, 20-60 years in the other UK study ${ }^{(21)}$ and $40-69$ years in the current study (UK Biobank).

Surprisingly, in the current study, South Asians in Greater London had a higher prevalence of vitamin-Dcontaining supplement use (35\%) than those in the other regions (18-28\%), who had lower odds of use by $28-54 \%$.
This was despite the model controlling for sex, ethnicity, BMI, age, gross annual household income and oily fish consumption, which warrants further investigation.

We found a slightly higher usage of vitamin-D-containing supplements in Indians compared with Bangladeshis and Pakistanis. However, this association disappeared when controlling for sex and age in the regression models. On the other hand, there were clear differences in vitamin D intake by ethnicity, with Bangladeshis having on average a higher vitamin D intake $(3.0 \mu \mathrm{g} / \mathrm{d})$ than Indians $(1.0 \mu \mathrm{g} / \mathrm{d})$ and Pakistanis $(1.5 \mu \mathrm{g} / \mathrm{d})$. South Asians are particularly underrepresented in UK-wide diet surveys so there is no national data with which to compare our findings, but our findings concur with a smaller UK cohort study reporting that South Asian women consume $1 \cdot 6-2 \cdot 2 \mu \mathrm{g}$ of vitamin D daily ${ }^{(9)}$ from their diet (excluding supplements). These estimates are 
slightly lower than the NDNS average intake of $1 \cdot 8-3 \cdot 2 \mu \mathrm{g} / \mathrm{d}$, based mainly on data from white Caucasians ${ }^{(26)}$.

The higher vitamin D intake in Bangladeshis is likely due to increased oily fish consumption relative to the other groups. Equally, the poor vitamin D intake in Indians is

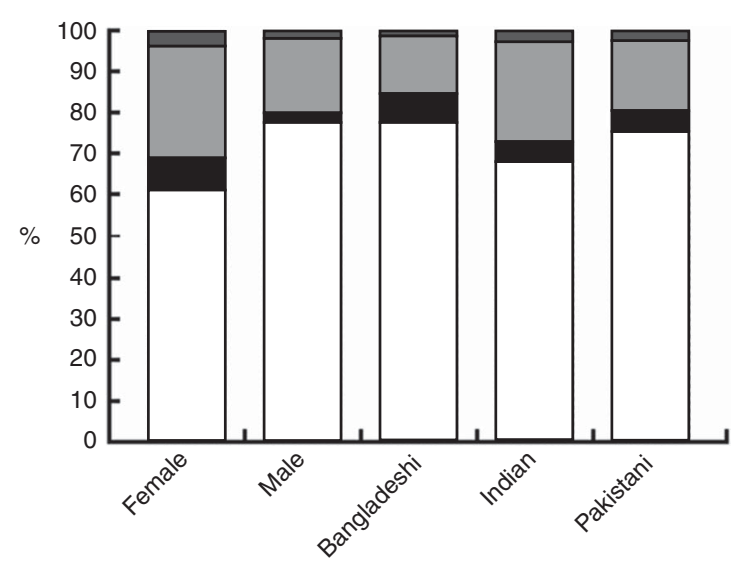

Fig. 2 Vitamin-D-containing supplement usage ( $\square$, vitamin $D$ and multivitamin; $\square$, multivitamin; $\square$, single vitamin $D$ supplement; $\square$, neither) by sex and ethnic group among 8024 South Asian UK Biobank participants. Women, and persons of Indian ethnicity, were more likely to use a vitamin-D-containing supplement than were men, and persons Bangladeshi and Pakistani ethnicity, respectively $\left(x^{2}\right.$ test, both $\left.P<0.001\right)$ likely due to the high prevalence of vegetarianism in this group. Eggs, cereals and fortified spreads are other sources of vitamin $\mathrm{D}$ that may be relevant in this group, but these sources are lower in vitamin D content than oily fish. The numbers are generally too small in the Bangladeshi group to make definitive inferences, but it is noteworthy that only $10 \%$ ( $n$ 22) of the Bangladeshi group ate oily fish daily. It is widely thought that this group is less vulnerable to vitamin D deficiency based on its traditional consumption of large amounts of oily fish. However, our findings support that of another UK research study which found that when food intake over the last $7 \mathrm{~d}$ was assessed, traditional dishes containing oily fish were consumed by only $7-50 \%$ of Bangladeshi households ${ }^{(43)}$.

Importantly, the dietary vitamin D intakes of all three ethnic groups are very low and not sufficient to meet the SACN recommendation of $10 \mu \mathrm{g}$ of vitamin D daily ${ }^{(4)}$. Therefore, there is a very urgent public health need to promote the use of vitamin-D-containing foods as well as supplements in South Asian populations.

To our knowledge, the present study is the first one ever to assess the demographic, dietary and lifestyle factors associated with vitamin D supplementation use among UK South Asians. In terms of internal validity, completion of the supplement use question was excellent with a $97 \%$ completion rate in the 8024 South Asians,

Table 3 Baseline odds of being a vitamin D supplement user (single vitamin D supplement, as part of multivitamin and mineral supplement, or both) among 8024 South Asian UK Biobank participants by demographic, dietary and anthropometric characteristics: logistic regression models 1 and 2

\begin{tabular}{|c|c|c|c|c|c|c|c|}
\hline Model & & $n$ & $B^{*}$ & SE & $\mathrm{OR} \dagger$ & $\begin{array}{l}\text { Lower } \\
95 \% \mathrm{Cl}\end{array}$ & $\begin{array}{l}\text { Upper } \\
95 \% \mathrm{Cl}\end{array}$ \\
\hline \multirow{11}{*}{$\begin{array}{l}\text { Model } 1(n 7753) \\
\qquad P<0.001 \\
\text { Nagelkerke } R^{2}=0.05 \\
\text { HL test, } P=0.31\end{array}$} & Sex & & & & & & \\
\hline & Female & 3611 & 0.76 & 0.05 & $2 \cdot 13$ & 1.93 & $2 \cdot 36$ \\
\hline & Male (reference) & 4142 & - & - & 1.00 & - & - \\
\hline & Ethnicity & & & & & & \\
\hline & Indian (reference) & 5793 & - & - & 1.00 & - & - \\
\hline & Pakistani & 1742 & -0.26 & 0.06 & 0.77 & 0.68 & 0.87 \\
\hline & Bangladeshi & 218 & -0.32 & 0.17 & 0.73 & 0.52 & 1.01 \\
\hline & Age (years) & & & & & & \\
\hline & $40-59$ & 5603 & -0.24 & 0.06 & 0.79 & 0.71 & 0.88 \\
\hline & $\geq 60$ (reference) & 2150 & - & - & 1.00 & - & - \\
\hline & Constant & & $-1 \cdot 32$ & 0.17 & 0.27 & & \\
\hline \multirow{14}{*}{$\begin{array}{l}\text { Model } 2(n 7538) \\
\quad P<0.001 \\
\text { Nagelkerke } R^{2}=0.05 \\
\text { HL test, } P=0.45\end{array}$} & Sex & & & & & & \\
\hline & Female & 3562 & 0.76 & 0.05 & $2 \cdot 15$ & 1.94 & $2 \cdot 38$ \\
\hline & Male (reference) & 3976 & - & - & 1.00 & - & - \\
\hline & Ethnicity & & & & & & \\
\hline & Indian (reference) & 5623 & - & - & $1 \cdot 00$ & - & - \\
\hline & Pakistani & 1703 & -0.23 & 0.07 & 0.80 & 0.70 & 0.90 \\
\hline & $\begin{array}{l}\text { Bangladeshi } \\
\text { BMI }\left(\mathrm{kg} / \mathrm{m}^{2}\right)\end{array}$ & 212 & -0.35 & 0.17 & 0.71 & 0.51 & 0.99 \\
\hline & $\leq 25.4$ (normal/underweight) & 2734 & 0.22 & 0.07 & $1 \cdot 25$ & $1 \cdot 10$ & 1.43 \\
\hline & $25 \cdot 5-29 \cdot 4$ (overweight) & 2818 & 0.08 & 0.07 & 1.08 & 0.95 & $1 \cdot 233$ \\
\hline & $>29.4$ (obese; reference) & 1986 & - & - & 1.00 & - & - \\
\hline & Age (years) & & & & & & \\
\hline & $40-59$ & 5447 & -0.23 & 0.06 & 0.79 & 0.71 & 0.885 \\
\hline & $\geq 60$ (reference) & 2091 & - & - & 1.00 & - & - \\
\hline & Constant & & -1.47 & $0 \cdot 18$ & 0.23 & & \\
\hline
\end{tabular}

$\mathrm{HL}$ test, Hosmer-Lemeshow test for fit of data for model (null hypothesis = satisfactory fit). 
Table 4 Baseline odds of being a vitamin D supplement user (single vitamin D supplement, as part of multivitamin and mineral supplement, or both) among 8024 South Asian UK Biobank participants by demographic, dietary and anthropometric characteristics: logistic regression models 3 and 4

\begin{tabular}{|c|c|c|c|c|c|c|c|}
\hline Model & & $n$ & $B^{\star}$ & SE & OR† & $\begin{array}{c}\text { Lower } \\
95 \% \mathrm{Cl}\end{array}$ & $\begin{array}{c}\text { Upper } \\
95 \% \mathrm{Cl}\end{array}$ \\
\hline Model 3 ( $n$ 5636) & Sex & & & & & & \\
\hline$P<0.001$ & Female & 2444 & 0.72 & 0.06 & 2.05 & 1.82 & $2 \cdot 31$ \\
\hline Nagelkerke $R^{2}=0.06$ & Male (reference) & 3192 & - & - & 1.00 & - & - \\
\hline \multirow[t]{24}{*}{ HL test, $P=0.31$} & Ethnicity & & & & & & \\
\hline & Indian (reference) & 4248 & - & - & 1.00 & - & - \\
\hline & Pakistani & 1247 & -0.05 & 0.08 & 0.95 & 0.81 & $1 \cdot 11$ \\
\hline & Bangladeshi & 141 & -0.31 & 0.22 & 0.73 & 0.48 & $1 \cdot 12$ \\
\hline & BMI $\left(\mathrm{kg} / \mathrm{m}^{2}\right)$ & & & & & & \\
\hline & $\leq 25.4$ (normal/underweight) & 2091 & 0.18 & 0.08 & 1.20 & 1.03 & 1.40 \\
\hline & $25.5-29.4$ (overweight) & 2100 & 0.02 & 0.08 & 1.02 & 0.87 & $1 \cdot 19$ \\
\hline & $>29.4$ (obese; reference) & 1445 & - & - & 1.00 & - & - \\
\hline & Age (years) & & & & & & \\
\hline & $40-59$ & 4177 & -0.29 & 0.07 & 0.75 & 0.65 & 0.85 \\
\hline & $\geq 60$ (reference) & 1459 & - & - & 1.00 & - & - \\
\hline & Gross annual household income $(£)$ & & & & & & \\
\hline & $<18000$ & 1776 & -0.23 & 0.09 & 0.80 & 0.67 & 0.94 \\
\hline & $18000-30999$ & 1341 & -0.02 & 0.09 & 0.98 & 0.83 & $1 \cdot 16$ \\
\hline & $31000-51999$ & 1152 & 0.12 & 0.09 & $1 \cdot 13$ & 0.95 & 1.34 \\
\hline & $\geq 52000$ (reference) & 1367 & - & - & 1.00 & - & - \\
\hline & Region & & & & & & \\
\hline & North England & 1341 & -0.28 & 0.08 & 0.76 & 0.65 & 0.89 \\
\hline & South England & 496 & -0.29 & $0 \cdot 11$ & 0.75 & 0.60 & 0.93 \\
\hline & Wales & 86 & -0.65 & 0.28 & 0.52 & 0.30 & 0.90 \\
\hline & Scotland & 136 & -0.47 & 0.21 & 0.63 & 0.41 & 0.95 \\
\hline & Midlands & 1148 & -0.30 & 0.08 & 0.74 & 0.63 & 0.87 \\
\hline & Greater London (reference) & 2429 & - & - & 1.00 & - & - \\
\hline & Constant & & $-1 \cdot 15$ & 0.24 & 0.32 & & \\
\hline \multirow{32}{*}{$\begin{array}{l}\text { Model } 4(n \text { 5512) } \\
\quad P<0.001 \\
\quad \text { Nagelkerke } R^{2}=0.06 \\
\text { HL test, } P=0.43\end{array}$} & Sex & & & & & & \\
\hline & Female & 2403 & 0.70 & 0.06 & 2.02 & 1.79 & $2 \cdot 28$ \\
\hline & Male & 3109 & - & - & 1.00 & - & - \\
\hline & Ethnicity & & & & & & \\
\hline & Indian (reference) & 4177 & - & - & 1.00 & - & - \\
\hline & Pakistani & 1196 & -0.04 & 0.08 & 0.96 & 0.82 & $1 \cdot 12$ \\
\hline & Bangladeshi & 139 & -0.38 & 0.22 & 0.69 & 0.45 & 1.06 \\
\hline & $\operatorname{BMI}\left(\mathrm{kg} / \mathrm{m}^{2}\right)$ & & & & & & \\
\hline & $\leq 25.4$ (normal/underweight) & 2055 & 0.20 & 0.08 & 1.22 & 1.04 & 1.42 \\
\hline & $25.5-29.4$ (overweight) & 2041 & 0.02 & 0.08 & 1.02 & 0.88 & 1.20 \\
\hline & $>29.4$ (obese; reference) & 1416 & - & - & 1.00 & - & - \\
\hline & Age (years) & & & & & & \\
\hline & $40-59$ & 4076 & -0.29 & 0.07 & 0.75 & 0.65 & 0.86 \\
\hline & $\geq 60$ (reference) & 1436 & - & - & 1.00 & - & - \\
\hline & Gross annual household income $(£)$ & & & & & & \\
\hline & $<18000$ & 1711 & -0.22 & 0.09 & 0.80 & 0.68 & 0.95 \\
\hline & $18000-30999$ & 1314 & -0.02 & 0.09 & 0.99 & 0.83 & 1.17 \\
\hline & $31000-51999$ & 1134 & 0.13 & 0.09 & $1 \cdot 14$ & 0.96 & 1.36 \\
\hline & $\geq 52000$ (reference) & 1353 & - & - & 1.00 & - & - \\
\hline & Region & & & & & & \\
\hline & North England & 1305 & -0.26 & 0.08 & 0.77 & 0.66 & 0.90 \\
\hline & South England & 487 & -0.29 & 0.11 & 0.75 & 0.60 & 0.93 \\
\hline & Wales & 85 & -0.64 & 0.28 & 0.53 & 0.31 & 0.91 \\
\hline & Scotland & 133 & -0.54 & 0.22 & 0.58 & 0.38 & 0.90 \\
\hline & Midlands & 1119 & -0.29 & 0.08 & 0.75 & 0.64 & 0.88 \\
\hline & Greater London (reference) & 2383 & - & - & 1.00 & - & - \\
\hline & Oily fish consumption & & & & & & \\
\hline & Never & 1672 & -0.14 & $0 \cdot 11$ & 0.87 & 0.70 & 1.07 \\
\hline & $<$ Once per week & 1713 & -0.25 & $0 \cdot 11$ & 0.78 & 0.63 & 0.96 \\
\hline & Once per week & 1519 & -0.04 & $0 \cdot 11$ & 0.96 & 0.78 & 1.19 \\
\hline & $\geq 2$ times per week (reference) & 608 & - & - & 1.00 & - & - \\
\hline & Constant & & -1.09 & 0.25 & 0.34 & & \\
\hline
\end{tabular}

$\mathrm{HL}$ test, Hosmer-Lemeshow test for fit of data for model (null hypothesis = satisfactory fit).

${ }^{*} B=$ unstandardised coefficient.

†OR $=$ odds of being a supplement user ( $v$. non-supplement user, $\mathrm{OR}=1.00)$.

which supports the representativeness of our findings within the UK Biobank cohort.

We undertook a retrospective power calculation for our main predictive factor on supplement use: sex (exposure $=$ sex, outcome $=$ supplement use). We had $80 \%$ power to observe an OR of $2 \cdot 2$, as $41 \%$ of controls (non-supplement users) and $60 \%$ of cases (supplement users) were female (exposed), and there was a ratio of controls to cases of 3.3. 
We had sufficient power as no OR for sex was larger than $2 \cdot 2$, except for the supplementary analysis for single vitamin D supplementation (excluding multivitamins) as seen in the online supplementary material, Supplemental Table 4.

Nevertheless, the study has a number of limitations which may affect its internal validity and warrant further discussion. First, due the wording of the supplement questions, we were not able to assess dosage or supplement brand, or season of supplement usage. The amount of vitamin $\mathrm{D}$ in both multivitamin and single vitamin supplements varies depending on brand used. For these reasons we were not able to assess the actual amount of vitamin D obtained from supplements in the current analysis. The $24 \mathrm{~h}$ dietary recall estimate did not include use of supplements, so actual vitamin D intakes were from diet only. Also, $24 \mathrm{~h}$ recall is not an ideal method for assessing vitamin $\mathrm{D}$ intake as many rich sources of vitamin $\mathrm{D}$ are often consumed only a few times per week (e.g. oily fish, eggs) and so may be missed if not consumed on the day of the recall.

Second, in terms of frequency of completion, only $18 \%$ of the South Asian participants completed a $24 \mathrm{~h}$ dietary recall at least once, and thus had an estimate for vitamin D intake, with only $9 \%$ completing a $24 \mathrm{~h}$ dietary recall more than once. This could be a source of bias as those who completed a higher number of recalls are likely to produce a more accurate estimate of vitamin $\mathrm{D}$ intake. Many participants did not have data for certain questions, excluding them from the modelling (see online supplementary material, Supplemental File 3, for details). Also, the questionnaire was designed for assessing a variety of nutrients, so may not give as accurate or valid estimate of vitamin D intake as would a questionnaire specific for vitamin D.

Third, not being able to include cod-liver oil consumption in the analysis, due to the relevant question only assessing fish oils in total (including $n$-3 supplements), may have led to a slight underestimation of vitamin-Dcontaining supplement use. Indeed, $13 \%$ of the South Asians who said that they were not taking a single vitamin D supplement or multivitamin supplement reported that they used fish oils. It is unclear as to how many of these participants consumed cod-liver oil (containing vitamin D) and how many consumed other fish oil (e.g. $n$-3; not containing vitamin D). Similarly, $2 \%$ of those who said they were not taking a single vitamin D supplement or multivitamin supplement reported that they took prescription medicines containing vitamin D. Therefore, actual vitamin-D-containing supplement use may be slightly underestimated in our analysis.

Fourth, due to a small sample size relative to the other ethnic groups, the results for the Bangladeshis ( $n$ 236) may lack robustness, particularly for vitamin D intake, whereby the number of Bangladeshis who completed at least one dietary recall was low ( $n$ 34; i.e. $14 \%$ of original sample) compared with that of the Indians (31\%) and Pakistanis (17\%). Finally, some UK-wide representativeness may be lost due to the fact that about two-thirds of the South Asians came from four UK Biobank assessment centres (Leeds, Hounslow, Croydon and Birmingham).

Despite these limitations which may affect internal validity of the present study, it is still the largest analysis of its kind to date, providing us with the most comprehensive examination of vitamin $\mathrm{D}$ exposure through either dietary intake or vitamin-D-containing supplement usage in Western-dwelling South Asian populations. Importantly, $37 \%$ of South Asians in our study live in areas below the UK census (2001) median Townsend Deprivation Index and $22 \%$ live in the lowest (most deprived) quartile (http://census.ukdataservice.ac.uk/get-data/related/depri vation). This means that our study is likely to be more representative of the UK South Asian population, and have stronger external validity, than is the case in some other nutritional research and surveys in this population, which tend to include mostly South Asians of higher socio-economic status. However, as with all studies, external validity is still slightly limited by the fact that, as research participants, they may differ in some factors (e.g. health-consciousness) than the general South Asian population, and these data cannot be used to estimate formal prevalence rates of vitamin-D-containing supplement use. Further work is now planned to link the vitamin $\mathrm{D}$ intakes and supplement usage with measurements of $25(\mathrm{OH}) \mathrm{D}$, which were not available at the time of the current analysis, in the South Asian subset of the UK Biobank cohort.

\section{Conclusion}

We have shown that vitamin D intakes in the UK Biobank South Asians were generally low but variable among South Asian sub-population groups, 1.0 to $3.0 \mu \mathrm{g} / \mathrm{d}$, and not affected by sex. We have also demonstrated that being of female sex was associated with increased odds of vitamin-D-containing supplement use, as was being of younger age and living in Greater London. We found borderline trends for lower BMI, higher household income and higher oily fish consumption being associated with increased odds of using a supplement containing vitamin $\mathrm{D}$.

These findings suggest that even in a research population, which is likely to be more health-conscious than the general population, current levels of vitamin-D-containing supplement use are very low and absolutely unlikely to be sufficient to ensure vitamin D sufficiency $(\geq 50 \mathrm{nmol} / \mathrm{l})$. There is a real need for development and implementation of public health strategies to promote the use of vitaminD-containing foods as well as supplements among UKdwelling South Asian populations, particularly in the light of the newly published UK vitamin D requirements ${ }^{(4)}$. 
Acknowledgements

Acknowledgements: This research has been conducted using the UK Biobank Resource under application number 15168. Financial support: This work was supported by inhouse funds from the University of Surrey for payment of the UK Biobank access fee. The UK Biobank was established by the Wellcome Trust medical charity, Medical Research Council, Department of Health, Scottish Government and Northwest Regional Development Agency. It has also had funding from the Welsh Assembly Government and the British Heart Foundation. UK Biobank is hosted by the University of Manchester and supported by the National Health Service (NHS). All the above funders had no role in the design, analysis or writing of the present article. Conflict of interest: S.A.L.-N. discloses that she is Research Director of D3-TEX Limited which holds the UK patent for the use of UVB-transparent clothing to prevent vitamin D deficiency, with a Gulf Corporation Council (GCC) patent pending. S.A.L.-N.'s husband, William Lanham-New, is Managing Director of D3-TEX Limited. S.A.L.-N. has received grants from: (i) the UK Biotechnology and Biological Sciences Research Council (BBSRC) (Project: Ergocalciferol (D2) v. Cholecalciferol (D3) Food Fortification: Comparative Efficiency in Raising 25OHD Status \& Mechanisms of Action (D2-D3 Study), BB/I006192/1, £516823); (ii) the UK Food Standards Agency (Project: Vitamin D, Food Intake, Nutrition and Exposure to Sunlight in Southern England (D-FINES) Study, N05064, £600 000); (iii) the European Union (Project: Food Based Solutions for Optimal Vitamin D Nutrition and Health Through the Life Cycle, Lead Work Package 4: Nutritional requirements for vitamin D during pregnancy, childhood and adolescence using RCTs, FP7-613977ODIN, €6.2 million); and (iv) the UK Ministry of Defence (MoD, $£ 2.4$ million). S.A.L.-N. is a current member of SACN and a member of the panel that was responsible for the most recent revision of vitamin $\mathrm{D}$ recommended nutritional intake guidelines in the UK. She is a board member for the UK National Osteoporosis Society and the British Nutrition Foundation. She is Secretary of the Nutrition Society as well as Editor-in-Chief of the Nutrition Society textbook series. All other authors have no conflict of interest. Authorship: Author contributions were as follows. Formulating the research question(s): A.L.D., D.J.B., K.R.A., S.A.L.-N. Designing the study: A.L.D., D.J.B., K.R.A., S.A.L.-N. Data collection: not applicable. Analysing the data: A.L.D., D.J.B., K.R.A., S.A.L-.N. Writing the article: A.L.D., D.J.B., K.R.A., S.A.L.-N. Ethics of human subject participations: The UK Biobank study is conducted according to the guidelines laid down in the Declaration of Helsinki and all procedures involving human subjects were approved by the UK North West Multi-centre Research Ethics Committee (MREC) (application 11/NW/ 0382). Written informed consent was obtained from all subjects.

\section{Supplementary material}

To view supplementary material for this article, please visit https://doi.org/10.1017/S1368980018001404

\section{References}

1. van Schoor NM \& Lips P (2011) Worldwide vitamin D status. Best Pract Res Clin Endocrinol Metab 25, 671-680.

2. Holick MF (2007) Vitamin D deficiency. N Engl J Med 357, 266-281.

3. Grant WB, Cross HS, Garland CF et al. (2009) Estimated benefit of increased vitamin D status in reducing the economic burden of disease in western Europe. Prog Biophys Mol Biol 99, 104-113.

4. Scientific Advisory Committee on Nutrition (2016) Vitamin D and Health. https://www.gov.uk/government/publications/ sacn-vitamin-d-and-health-report (accessed June 2017).

5. European Food Safety Authority (2016) Scientific Opinion on Dietary Reference Values for vitamin D. https://www. efsa.europa.eu/sites/default/files/consultation/160321.pdf (accessed August 2017).

6. Xiao CW, Wood CM, Swist E et al. (2016) Cardio-metabolic disease risks and their associations with circulating 25hydroxyvitamin D and omega-3 levels in South Asian and white Canadians. PLoS One 11, e0147648.

7. Garcia-Bailo B, Karmali M, Badawi A et al. (2013) Plasma 25-hydroxyvitamin D, hormonal contraceptive use, and cardiometabolic disease risk in an ethnically diverse population of young adults. J Am Coll Nutr 32, 296-306.

8. Sham L, Yeh EA, Magalhaes S et al. (2015) Evaluation of fall sun exposure score in predicting vitamin D status in young Canadian adults, and the influence of ancestry. J Photochem Photobiol B 145, 25-29.

9. Darling AL, Hart KH, Macdonald HM et al. (2013) Vitamin D deficiency in UK South Asian women of childbearing age: a comparative longitudinal investigation with UK Caucasian women. Osteoporos Int 24, 477-488.

10. Lowe NM, Mitra SR, Foster PC et al. (2010) Vitamin D status and markers of bone turnover in Caucasian and South Asian postmenopausal women living in the UK. Br J Nutr 103, 1706-1710.

11. Eggemoen AR, Falk RS, Knutsen KV et al. (2016) Vitamin D deficiency and supplementation in pregnancy in a multiethnic population-based cohort. BMC Pregnancy Childbirth 16, 7.

12. Mavroeidi A, O'Neill F, Lee PA et al. (2010) Seasonal 25hydroxyvitamin D changes in British postmenopausal women at 57 degrees $\mathrm{N}$ and 51 degrees $\mathrm{N}$ : a longitudinal study. J Steroid Biochem Mol Biol 121, 459-461.

13. Darling AL, Hart KH, Gibbs MA et al. (2014) Greater seasonal cycling of 25-hydroxyvitamin D is associated with increased parathyroid hormone and bone resorption. Osteoporos Int 25, 933-941.

14. Papadakis G, Zambelis T, Villiotou V et al. (2015) Lower levels of vitamin D among Bangladeshi immigrants with diabetes in Greece compared to indigenous Greek patients with diabetes. In Vivo 29, 541-545.

15. Franchi B, Piazza M, Sandri M et al. (2015) 25Hydroxyvitamin D serum level in children of different ethnicity living in Italy. Eur J Pediatr 174, 749-757.

16. Macdonald HM, Mavroeidi A, Fraser WD et al. (2011) Sunlight and dietary contributions to the seasonal vitamin D status of cohorts of healthy postmenopausal women living at northerly latitudes: a major cause for concern? Osteoporos Int 22, 2461-2472.

17. van der Meer IM, Middelkoop BJ, Boeke AJ et al. (2011) Prevalence of vitamin D deficiency among Turkish, Moroccan, Indian and sub-Sahara African populations in Europe 
and their countries of origin: an overview. Osteoporos Int 22, 1009-1021.

18. Holvik K, Meyer HE, Haug E et al. (2005) Prevalence and predictors of vitamin D deficiency in five immigrant groups living in Oslo, Norway: the Oslo Immigrant Health Study. Eur J Clin Nutr 59, 57-63.

19. von Hurst PR, Stonehouse W \& Coad J (2010) Vitamin D status and attitudes towards sun exposure in South Asian women living in Auckland, New Zealand. Public Health Nutr 13, 531-536.

20. Libon F, Cavalier E \& Nikkels AF (2013) Skin color is relevant to vitamin D synthesis. Dermatology 227, 250-254.

21. Kift R, Berry JL, Vail A et al. (2013) Lifestyle factors including less cutaneous sun exposure contribute to starkly lower vitamin D levels in UK South Asians compared with the white population. Br J Dermatol 169, 1272-1278.

22. Kotta S, Gadhvi D, Jakeways N et al. (2015) 'Test me and treat me' - attitudes to vitamin D deficiency and supplementation: a qualitative study. BMJ Open 5, e007401.

23. Donin AS, Nightingale CM, Owen CG et al. (2010) Nutritional composition of the diets of South Asian, black AfricanCaribbean and white European children in the United Kingdom: the Child Heart and Health Study in England (CHASE). Br J Nutr 104, 276-285.

24. Lyratzopoulos G, McElduff P, Heller RF et al. (2005) Comparative levels and time trends in blood pressure, total cholesterol, body mass index and smoking among Caucasian and SouthAsian participants of a UK primary-care based cardiovascular risk factor screening programme. BMC Public Health 5, 125.

25. Barnett AH, Dixon AN, Bellary S et al. (2006) Type 2 diabetes and cardiovascular risk in the UK South Asian community. Diabetologia 49, 2234-2246.

26. Whitton C, Nicholson SK, Roberts C et al. (2011) National Diet and Nutrition Survey: UK food consumption and nutrient intakes from the first year of the rolling programme and comparisons with previous surveys. Br J Nutr 106, 1899-1914.

27. Lu Z, Chen TC, Zhang A et al. (2007) An evaluation of the vitamin $\mathrm{D}_{3}$ content in fish: is the vitamin $\mathrm{D}$ content adequate to satisfy the dietary requirement for vitamin D? J Steroid Biochem Mol Biol 103, 642-644.

28. Black LJ, Jacoby P, Nowson CA et al. (2016) Predictors of vitamin D-containing supplement use in the Australian population and associations between dose and serum 25hydroxyvitamin D concentrations. Nutrients 8, E356.

29. Greene-Finestone LS, Langlois KA \& Whiting SJ (2013) Characteristics of users of supplements containing vitamin D in Canada and associations between dose and 25hydroxvitamin D. Appl Physiol Nutr Metab 38, 707-715.

30. Sudlow C, Gallacher J, Allen N et al. (2015) UK Biobank: an open access resource for identifying the causes of a wide range of complex diseases of middle and old age. PLoS Med 12, e1001779.

31. UK Biobank (2012) 24-hour Dietary Recall Questionnaire Version 1.1. http://biobank.ctsu.ox.ac.uk/crystal/docs/ DietWebQ.pdf (accessed December 2016).

32. Liu B, Young H, Crowe FL et al. (2011) Development and evaluation of the Oxford WebQ, a low-cost, web-based method for assessment of previous $24 \mathrm{~h}$ dietary intakes in large-scale prospective studies. Public Health Nutr 14, 1998-2005.

33. Holland B, Welch AA, Unwin ID et al. (1991) McCance and Widdowson's The Composition of Foods, 5th ed. Cambridge: Royal Society of Chemistry.

34. OU Cancer Epidemiology Unit (n.d.) OxfordWebQ Online. https://questionnaires.ceu.ox.ac.uk/diet/show/login.html (accessed June 2016).

35. Black LJ, Walton J, Flynn A et al. (2015) Small increments in vitamin D intake by Irish adults over a decade show that strategic initiatives to fortify the food supply are needed. J Nutr 145, 969-976.

36. Alberti KG, Zimmet P \& Shaw J (2007) International Diabetes Federation: a consensus on type 2 diabetes prevention. Diabet Med 24, 451-463.

37. Bodicoat DH, Gray LJ, Henson J et al. (2014) Body mass index and waist circumference cut-points in multi-ethnic populations from the UK and India: the ADDITION-Leicester, Jaipur heart watch and New Delhi cross-sectional studies. PLoS One 9, e90813.

38. Kofoed CL, Christensen J, Dragsted LO et al. (2015) Determinants of dietary supplement use - healthy individuals use dietary supplements. Br J Nutr 113, 1993-2000.

39. Li K, Kaaks R, Linseisen J et al. (2010) Consistency of vitamin and/or mineral supplement use and demographic, lifestyle and health-status predictors: findings from the European Prospective Investigation into Cancer and Nutrition (EPIC)-Heidelberg cohort. Br J Nutr 104, 1058-1064.

40. Cline RR \& Worley MM (2006) Osteoporosis health beliefs and self-care behaviors: an exploratory investigation. $\mathrm{J} \mathrm{Am}$ Pharm Assoc (2003) 46, 356-363.

41. Meyer HE, Holvik K, Lofthus CM et al. (2008) Vitamin D status in Sri Lankans living in Sri Lanka and Norway. $\mathrm{Br} \mathrm{J}$ Nutr 99, 941-944.

42. Ginter JK, Krithika S, Gozdzik A et al. (2013) Vitamin D status of older adults of diverse ancestry living in the Greater Toronto Area. BMC Geriatr 13, 66.

43. Kassam-Khamis T, Judd PAT \& Homas JE (2000) Frequency of consumption and nutrient composition of composite dishes commonly consumed in the UK by South Asian Muslims originating from Bangladesh, Pakistan and East Africa (Ismailis). J Hum Nutr Diet 13, 185-196. 